\title{
Armazenamento refrigerado de morango submetido a altas concentrações de $\mathrm{CO}_{2}$
}

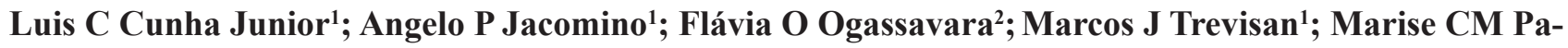 \\ risi $^{3}$ \\ ${ }^{1}$ USP-ESALQ, Depto. Prod. Vegetal, C. Postal 9, 13418-900 Piracicaba-SP; luiscarloscunha@hotmail.com; jacomino@esalq.usp.br; \\ mjtrevis@esalq.usp.br; ${ }^{2}$ UNESP, Rodov. Prof. Paulo Donato Castellane s/n, 14884-900 Jaboticabal-SP; flaviaokog@hotmail.com; ${ }^{3}$ IB, \\ Av. Conselheiro Rodrigues Alves 1.252, 04014-002 Campinas-SP; marise@biologico.sp.gov.br
}

\begin{abstract}
RESUMO
Temperatura de $0^{\circ} \mathrm{C}$ associada a atmosferas com 12 a $20 \%$ de $\mathrm{CO}_{2}$ têm sido recomendadas como condição ideal para o armazenamento de morango. Entretanto, as redes de distribuição e comercialização de produtos hortícolas no Brasil geralmente não possuem cadeia de frio, ou a possuem em temperatura entre 10 e $15^{\circ} \mathrm{C}$. Este trabalho teve como objetivo avaliar a qualidade e conservação do morango 'Oso Grande' sob temperatura de $10^{\circ} \mathrm{C}$ associada com altas concentrações de dióxido de carbono. Os morangos foram selecionados, resfriados e armazenados a $10^{\circ} \mathrm{C}$ em mini-câmaras herméticas, onde foram aplicadas as distintas concentrações de $\mathrm{CO}_{2}(0,03,10,20,40$ e $80 \%)$ combinadas com $20 \%$ de $\mathrm{O}_{2}$. Os morangos foram avaliados a cada 2 dias até se tornarem impróprios para o consumo. As concentrações de 20 e $40 \%$ de $\mathrm{CO}_{2}$ permitiram a conservação dos morangos por até 8 dias; já aqueles com $0,03 \%$ de $\mathrm{CO}_{2}$ duraram apenas 2 dias. Os morangos a $80 \%$ de $\mathrm{CO}_{2}$ mantiveram ótima aparência por 6 dias, porém foram considerados inadequados para o consumo por apresentarem elevados teores de acetaldeído $\left(40,92 \mu \mathrm{g} \mathrm{g}^{-1}\right)$ e de etanol $(1.053 \mu \mathrm{g}$ $\left.\mathrm{g}^{-1}\right)$, provenientes do processo fermentativo. A perda de massa fresca dos morangos foi inferior a $2 \%$, demonstrando a eficiência da técnica utilizada para o controle da umidade relativa no armazenamento. Os frutos acondicionados com 0,03 e $80 \%$ de $\mathrm{CO}_{2}$ apresentaram a maior perda de firmeza, sendo que ao final do armazenamento esta foi de $40 \%$ em relação à firmeza inicial. Já os morangos armazenados com 20 e $40 \%$ de $\mathrm{CO}_{2}$ perderam apenas $28 \%$ da firmeza inicial. Apesar da diferença estatística na coloração externa do morango, essa foi visualmente imperceptível. Os morangos 'Oso Grande' armazenados a $10^{\circ} \mathrm{C}$ sob atmosfera controlada com $40 \%$ de $\mathrm{CO}_{2}$ associado com $20 \%$ de $\mathrm{O}_{2}$ mantiveram suas características comerciais por 8 dias.
\end{abstract}

Palavras-chave: Fragaria $x$ ananassa, atmosfera controlada, qualidade pós-colheita.

\section{ABSTRACT \\ Cold storage of strawberries under high $\mathrm{CO}_{2}$ concentrations}

Temperature of $0^{\circ} \mathrm{C}$ associated to $12-20 \% \mathrm{CO}_{2}$ has been recommended as the ideal conditions to store strawberries. However, fruits and vegetables are not currently handled under cold chain in Brazil and, when it happens, it used to be at 10 to $15^{\circ} \mathrm{C}$. The goal of this work was to evaluate the quality and the shelf life of 'Oso Grande' strawberry at $10^{\circ} \mathrm{C}$ associated to high carbon dioxide concentrations. Strawberries were randomized, chilled and stored at $10^{\circ} \mathrm{C}$ in hermetic mini-chambers to apply the $\mathrm{CO}_{2}$ concentrations $(0.03,10,20,40$ and $80 \%$ ) plus $20 \% \mathrm{O}_{2}$. Strawberries were analyzed every two days while they were proper to consumption. The shelf life for strawberries at 20 and $40 \% \mathrm{CO}_{2}$ was 8 days, while those at $0.03 \% \mathrm{CO}_{2}$ lasted only two days. Strawberries at $80 \% \mathrm{CO}_{2}$ maintained good appearance for 6 days, but they were considered unsuitable for consumption due to high levels of acetaldehyde (40.92 $\left.\mu \mathrm{g} \mathrm{g}^{-1}\right)$ and ethanol $\left(1,053 \mu \mathrm{g} \mathrm{g}^{-1}\right)$ that gave evidence of fermentation process. The weight loss was less than $2 \%$ showing how efficient was the method used to control the relative humidity during the storage. Strawberries at 0.03 and $80 \%$ $\mathrm{CO}_{2}$ levels showed higher firmness loss. Those fruits lost $40 \%$ of the initial firmness. Strawberries at 20 and $40 \% \mathrm{CO}_{2}$ lost only $28 \%$ of initial firmness. Despite of the statistical effect of the treatments in the external color it was not visually perceptible. Strawberries stored at $10^{\circ} \mathrm{C}$ and $40 \% \mathrm{CO}_{2}$ plus $20 \% \mathrm{O}_{2}$ kept the marketable quality during 8 days.

Keywords: Fragaria $x$ ananassa, controlled atmosphere, postharvest quality.

\section{(Recebido para publicação em 8 de dezembro de 2011; aceito em 16 de novembro de 2012) (Received on December 8, 2011; accepted on November 16, 2012)}

$\mathrm{O}$ morango (Fragaria x ananassa) é considerado um dos frutos mais importantes do mundo, por ser matéria prima de diversos alimentos. Como fruto in natura, é destinado à sobremesa, muito delicado e com elevado retorno financeiro ao produtor. $\mathrm{O}$ fruto apresenta características peculiares que agradam o consumidor como a cor vermelho-brilhante intensa, odor envolvente, textura macia e sabor levemente acidificado.
A produção brasileira de morango tem aumentado nos últimos anos. Estima-se uma área plantada de 3.500 ha, produzindo cerca de $100 \mathrm{mil} \mathrm{t}$ /ano. A produção está concentrada nas regiões sul e sudeste do país, sendo os estados de MG, SP e RS os maiores produtores. Por se tratar de uma cultura que abrange um grande contingente de mão-de-obra, o morango apresenta grande importância social e econômica (Antunes et al.,
2007).

A comercialização de morangos a grandes distâncias é dificultada devido à sua perecibilidade, decorrente principalmente da suscetibilidade ao desenvolvimento de agentes patogênicos. $\mathrm{O}$ principal método utilizado para minimizar esse efeito é o armazenamento refrigerado em temperaturas entre 0 e $1^{\circ} \mathrm{C}$. Esta técnica tem sido empregada com sucesso nos Estados Unidos e em países 
da Europa. Entretanto, a refrigeração é pouco utilizada na conservação de frutas e hortaliças no Brasil e, quando ocorre, geralmente utilizam-se temperaturas entre 10 e $15^{\circ} \mathrm{C}$. Sendo assim, estudos que proporcionem o armazenamento deste fruto, em temperaturas superiores a $0^{\circ} \mathrm{C}$ se tornam necessários.

Dentre os diversos métodos de conservação associados à refrigeração, destaca-se o uso de atmosfera controlada (AC), atmosfera modificada (AM), atmosfera inseticida, e tratamentos de pré-acondicionamento com dióxido de carbono $\left(\mathrm{CO}_{2}\right)$ (Flores-Cantillano, 2005). Para o morango, o armazenamento em atmosfera com níveis de $\mathrm{CO}_{2}$ entre $12 \%$ e $20 \%$ possibilita o aumento da vida útil do fruto e reduz a incidência de doenças, favorecendo a manutenção da firmeza (Almenar et al., 2006).

A escolha de uma embalagem adequada para conservação de morangos requer o conhecimento de diversas variáveis como respiração do fruto e permeabilidade da embalagem. Por sua vez, esses fatores, são dependentes da temperatura, já que a elevação da mesma promove aumento da taxa respiratória dos produtos e da permeabilidade do filme utilizado (Fonseca et al., 2002). Usualmente o morango é embalado em pequenas bandejas de tereftalato de polietileno (PET) com capacidade de 200 a $500 \mathrm{~g}$ revestido com filme de policloreto de vinila (PVC), que são pouco eficientes na modificação atmosférica. Uma das formas para determinar o sistema de embalagem apropriado para morango consiste em realizar testes utilizando atmosfera controlada sob a temperatura requerida de armazenamento. Desta forma, obtem-se as concentrações críticas de $\mathrm{CO}_{2}$ e $\mathrm{O}_{2}$, essenciais na escolha do material de embalagem.

Diversos estudos com atmosfera controlada, associada a temperaturas entre 0 e $5^{\circ} \mathrm{C}$ demonstraram que o uso de altas pressões parciais de $\mathrm{CO}_{2}$ atuaram diretamente no metabolismo dos frutos e/ou sobre a germinação e desenvolvimento de agentes patogênicos. Para o armazenamento de morango, elevadas concentrações de $\mathrm{CO}_{2}$ foram eficientes na redução de perdas causadas por patógenos, principalmente por Botrytis cineria (Van der Steen et al., 2002).
Brackmann et al. (2001), estudando atmosfera controlada com diferentes concentrações de $\mathrm{CO}_{2}(0,10,15$ e $20 \%)$, observaram que a combinação de $20 \%$ de $\mathrm{CO}_{2}$ e baixa temperatura $\left(0^{\circ} \mathrm{C}\right)$ propiciaram vida útil de 20 dias em morangos 'Oso Grande', sem ocasionar desordens fisiológicas.

Atmosferas com elevadas concentrações de $\mathrm{CO}_{2}$ (maiores que $20 \%$ ) podem ocasionar danos aos morangos, como o desenvolvimento de "off-flavor", perda na coloração da polpa e de aroma (Brackmann et al., 2001). Estudos realizados por Ke et al. (1993) reportam que concentrações de 20 a $30 \%$ de $\mathrm{CO}_{2}$ em morangos acarretaram aumento nas concentrações de acetaldeído e etanol. Entretanto, a concentração de $\mathrm{CO}_{2}$ danosa ao vegetal pode variar entre cultivar, ponto de colheita e temperatura de armazenamento, entre outros fatores (Chitarra \& Chitarra, 2005).

As redes de distribuição e comercialização de produtos hortícolas no Brasil não estão preparadas para utilizar a temperatura de $0^{\circ} \mathrm{C}$. Na verdade, quando apresentam cadeia de frio, esta é, geralmente, com temperatura entre 10 e $15^{\circ} \mathrm{C}$. Por isso, há necessidade de estudos pós-colheita de morango em temperatura comumente utilizada no comércio, uma vez que a maioria dos estudos para morango é com temperatura entre 0 e $5^{\circ} \mathrm{C}$.

Diante do exposto, o objetivo deste experimento foi avaliar a qualidade de morangos da cultivar Oso Grande armazenados à temperatura de $10^{\circ} \mathrm{C}$ associada à atmosfera controlada com altas concentrações de $\mathrm{CO}_{2}$.

\section{MATERIAL E MÉTODOS}

Morangos da cultivar Oso Grande foram colhidos em pomar comercial no município de Valinhos-SP (2258'S; $\left.16^{\circ} 59^{\prime} \mathrm{O}\right)$, nas primeiras horas do dia, com $50-75 \%$ da superfície de cor vermelho-brilhante, conforme recomendação de Flores-Cantillano (2005). Após a colheita, os frutos foram cuidadosamente transportados para o laboratório da ESALQ em Piracicaba-SP. Os morangos foram criteriosamente selecionados, com retirada dos frutos com podridão, ferimentos ou coloração inadequada. Após a homogeneização do lote, os morangos foram acondicionados em câmara frigorífica a $10^{\circ} \mathrm{C}$ para retirada do calor de campo. A aplicação dos tratamentos teve inicio quando a temperatura da polpa atingiu aproximadamente $12^{\circ} \mathrm{C}$.

Os morangos selecionados e pré-refrigerados foram armazenados em mini-câmaras, com capacidade de acondicionamento de aproximadamente $1,2 \mathrm{~kg}$ de morango, em camada única. As misturas gasosas foram umidificadas e injetadas na parte inferior da mini-câmara (entrada), com saída na parte superior e oposta à entrada, em fluxo contínuo de $150 \mathrm{~mL} \mathrm{~min}^{-1}$.

$\mathrm{O}$ equipamento utilizado para estabelecer e controlar a atmosfera foi o fluxcentro ("Flowboard") descrito por Calbo (1989), com modificação no regulador de pressão, utilizando-se uma válvula diferencial, utilizada em botijão de gás GLP doméstico, para regular a pressão do equipamento sem perda de gás, a qual ocorre quando se usa um barostato (Cerqueira et al., 2009).

Foram utilizadas cinco misturas gasosas com as concentrações de $\mathrm{CO}_{2}$ : $10,20,40$ e $80 \%$ combinadas com $20 \%$ de $\mathrm{O}_{2}$. O tratamento controle foi constituído por $0,03 \%$ de $\mathrm{CO}_{2}$ e $20 \%$ de $\mathrm{O}_{2}$. As misturas foram aferidas diariamente usando-se um analisador de gases da marca Dansensor, modelo Checkmate 9001.

Os morangos foram armazenados por até 8 dias em câmara a $10 \pm 1^{\circ} \mathrm{C}$. A umidade relativa no interior das mini-câmaras foi mantida a $95 \pm 2 \%$ UR, e as avaliações foram realizadas a cada 2 dias para as variáveis descritas a seguir.

A aparência foi avaliada segundo escala de notas, onde $3=$ ótimo (sem sintomas de doença; túrgido; com cor característica); $2=$ bom (sem sintomas de doença; com cor característica; sem turgidez); 1= ruim (sem sintomas de doença; sem cor característica; sem turgidez); e $0=$ péssimo (com sintomas de doença). As notas foram atribuídas para o conjunto de frutos contidos em 3 mini-câmaras. Morangos com nota 1 foram considerados impróprios para a comercialização.

A perda acumulada de massa fresca 
foi calculada em função da variação da massa das repetições, através da pesagem em balança semi-analítica, com precisão de 0,01 grama e os resultados expressos em porcentagem.

A firmeza da polpa foi determinada com penetrômetro digital marca Tr-Turoni, Sammar 53200 diretamente na lateral dos frutos com ponteira de $6 \mathrm{~mm}$, sendo utilizado 30 frutos por repetição e os resultados expressos em Newton (N).

A coloração externa foi determinada nos dois lados de cada fruto, sendo utilizados 30 frutos por repetição, com colorímetro Minolta, modelo CR-300, e os resultados expressos em luminosidade, ângulo de cor e cromaticidade, de acordo com McGuire (1992).

Os teores de acidez total titulável e sólidos solúveis foram determinados de acordo com AOAC (2005) e o de ácido ascórbico de acordo com Strocker \& Henning (1967). Para estas análises utilizou-se polpa homogeneizada de 30 frutos.

No preparo das amostras para quantificar os teores de acetaldeído e etanol, amostras de $1 \mathrm{~g}$ de polpa triturada foram seladas em frascos de $40 \mathrm{~mL}$, os quais foram lacrados e mantidos a $-12^{\circ} \mathrm{C}$ até o momento da análise. $\mathrm{Na}$ mesma amostra foram quantificados os teores de acetaldeído e etanol. A curva padrão de acetaldeído foi preparada pesando-se 0,085 g de acetaldeído e completando-se o volume para $400 \mathrm{~mL}$ com água deionizada gelada. Desta solução pipetaram-se 1,0 mL; 10,0 mL e 20,0 mL para balões volumétricos de $100 \mathrm{~mL}$, cujo volume foi completado com água deionizada gelada. Esta solução foi homogeneizada e transferida para frascos herméticos. A curva padrão de etanol foi preparada pesando-se 0,01 g; 0,14 g e 0,81 g de etanol para balões volumétricos de 200 $\mathrm{mL}$, cujo volume foi completado com água deionizada gelada. Esta solução foi homogeneizada e transferida para frascos herméticos. A determinação dos dois compostos se deu transferindo 1,0 mL de cada solução padrão para frascos de $40 \mathrm{~mL}$, onde foram lacrados e mantidos em banho-maria a $50^{\circ} \mathrm{C}$ por 30 minutos. Coletou-se 1,0 mL de ar do espaço livre (head space) do frasco, que foi analisado em cromatógrafo a gás (Thermofinnigan, modelo GC Trace
2000). Este procedimento também foi o mesmo adotado para as amostras, após o descongelamento por 1 hora em temperatura ambiente. Os resultados foram expressos em mg de acetaldeído ou etanol por 100 gramas de material vegetal.

Utilizou-se o delineamento inteiramente casualizado, em esquema fatorial $5 \times 5$. Os fatores foram constituídos pelo período de armazenamento $(0,2,4,6 \mathrm{e}$ 8 dias) e pelas atmosferas $(0,03,10,20$, 40 e $80 \%$ de $\mathrm{CO}_{2}$ ).

Para as variáveis de qualidade química (teores de acidez titulável, ácido ascórbico e sólidos solúveis) foram utilizadas quatro repetições, com 30 morangos por dia de análise. Para a firmeza da polpa e a coloração externa foram utilizadas 30 repetições, sendo constituídas de um fruto cada.

Os dados foram submetidos à análise de variância, análise de regressão polinomial e teste de médias (Tukey ao nível de $5 \%$ de probabilidade). Os teores de acetaldeído e etanol foram avaliados pelo erro padrão, cujas diferenças entre as médias de dois tratamentos sendo maior que a soma de dois erros padrões, foram consideradas significativas (Shamaila et al., 1992).

\section{RESULTADOS E DISCUSSÃO}

A atmosfera com $80 \%$ de $\mathrm{CO}_{2}$ preservou a aparência dos morangos até o $6^{\circ}$ dia de armazenamento, porém foram descartados por apresentarem odor alcoólico. A atmosfera com 40\% de $\mathrm{CO}_{2}$ manteve os frutos com aparência comercializável (nota $>1$ ) até o $8^{\circ}$ dia de armazenamento, enquanto no tratamento com $0,03 \%$ de $\mathrm{CO}_{2}$ os morangos encontravam-se comercializáveis por apenas 2 dias (Figura 1A).

Chitarra \& Chitarra (2005) recomendam temperatura de $0^{\circ} \mathrm{C}$ e umidade relativa de 90 a 95\% para conservação de morango. Todavia, condições de baixa temperatura $\left(0^{\circ} \mathrm{C}\right)$ raramente são encontradas nos estabelecimentos de comercialização de frutas e hortaliças, por isso a conservação por oito dias em atmosfera com $40 \%$ de $\mathrm{CO}_{2}$ associada à temperatura de $10^{\circ} \mathrm{C}$, pode ser mais viável.

O reduzido tempo de conservação pós-colheita de morango é afetado diretamente pelas doenças pós-colheita; assim tornam-se importantes tratamentos que contribuem para redução de doenças. Os tratamentos com altos teores de $\mathrm{CO}_{2}$ (20 a 40\%) estudados neste trabalho reduziram a incidência de podridões, mostrando potencial de uso em morango da cv. Oso Grande.

Ocorreu aumento significativo tanto para acetaldeído $\left(1.053 \mu \mathrm{g} \mathrm{g}^{-1}\right.$, Figura 1C) como para etanol $\left(40,92 \mu \mathrm{g} \mathrm{g}^{-1}\right.$, Figura 1B) nos morangos armazenados com $80 \%$ de $\mathrm{CO}_{2}$, impossibilitando a comercialização. Os frutos armazenados com $0,03 \%$ de $\mathrm{CO}_{2}$ não apresentaram alterações nos níveis de acetaldeído e etanol durante o armazenamento; os valores médios foram de $1,38 \mu \mathrm{g} \mathrm{g}^{-1} \mathrm{e}$ $29,37 \mu \mathrm{g} \mathrm{g}^{-1}$, respectivamente. Nos demais tratamentos foi observado aumento apenas no teor de etanol (Figura 1B) porém, sem reflexo aparente no odor dos morangos.

As atmosferas com 10, 20 e 40\% de $\mathrm{CO}_{2}$ exibiram aumento nos teores de etanol até o sexto dia de armazenamento, quando o valor médio dos tratamentos foi de $410 \mu \mathrm{g} \mathrm{g}^{-1}$, mantendo-se praticamente estável até o final do armazenamento. Já os teores de acetaldeído destes tratamentos não diferiram do controle com valor médio de $1,7 \mu \mathrm{g} \mathrm{g}^{-1}$ (Figura 1B e 1C).

Fernández-Trujillo et al. (2007), armazenando morango 'Jewel' em ar enriquecido com $20 \%$ de $\mathrm{CO}_{2}$ a $2^{\circ} \mathrm{C}$, observaram aumento nas concentrações de acetaldeído, etanol e acetato de etila, sendo que os maiores acúmulos desses compostos foram após o quarto dia de armazenamento. Resultados similares foram observados nesse trabalho para as atmosferas constituídas por 10, 20 e $40 \%$ de $\mathrm{CO}_{2}$ a $10^{\circ} \mathrm{C}$. Já os frutos acondicionados em $80 \%$ de $\mathrm{CO}_{2}+20 \%$ de $\mathrm{O}_{2}$ na mesma temperatura, apresentaram odor característico de fermentação no sexto dia.

Em morangos acondicionados em atmosfera com $20 \%$ de $\mathrm{CO}_{2}$ a $5^{\circ} \mathrm{C}$, foram detectados aumentos nas concentrações de acetaldeído e de etanol, sendo que estes representaram 57 e $63 \%$ dos voláteis totais, respectivamente (Zaldivar et al., 2007). O acúmulo de metabólico fermentativo pode ser uma resposta fisio- 


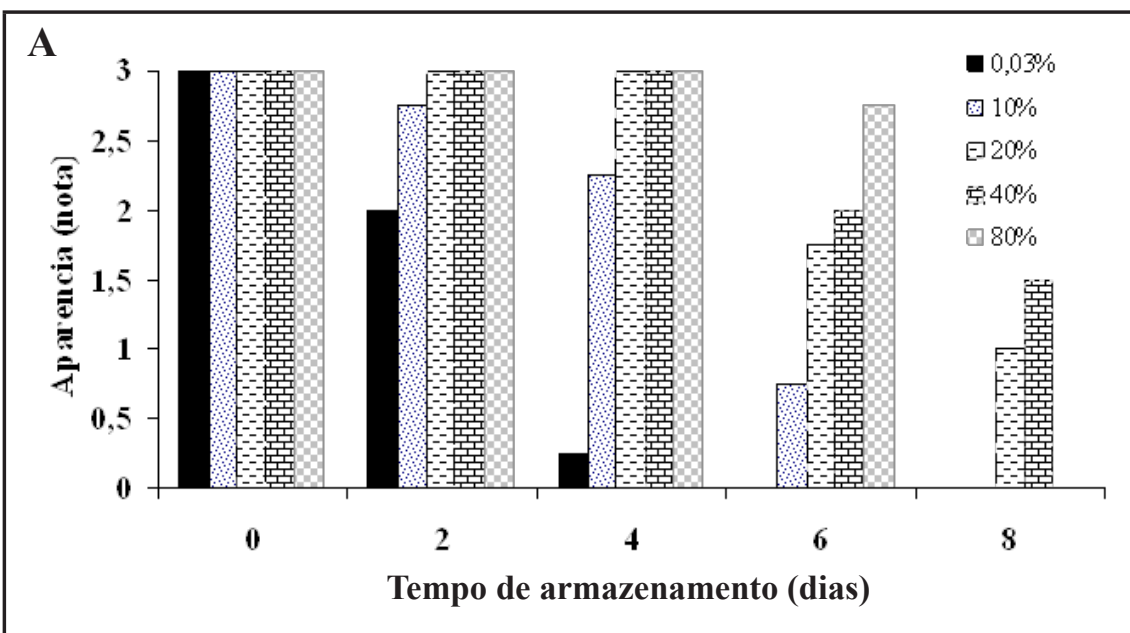

B
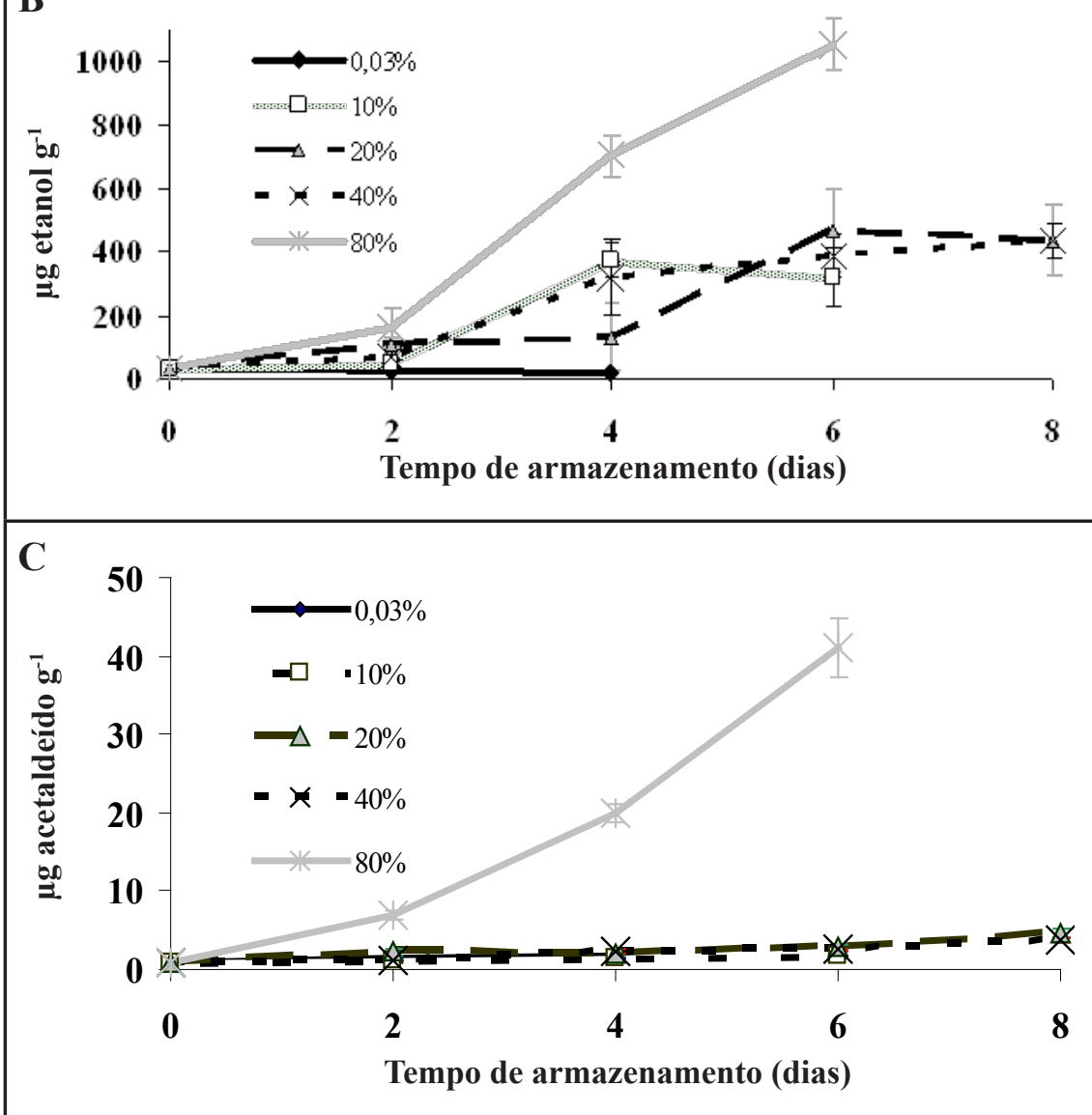

Figura 1. Aparência (A), teor de etanol (B) e acetaldeído (C) em morangos 'Oso Grande' submetidos a atmosfera controlada com distintas concentrações de $\mathrm{CO}_{2}$ associadas a $20 \%$ de $\mathrm{O}_{2}$, em armazenamento refrigerado $\left(10 \pm 1^{\circ} \mathrm{C}\right.$ e $95 \pm 2 \%$ UR). As barras verticais indicam o erro $(\mathrm{B}, \mathrm{C})$. Notas de aparência: $3=$ ótimo; $2=$ bom; $1=$ ruim; e $0=$ péssimo (appearance (A), ethanol (B) and acetaldehyde (C) levels in strawberries 'Oso Grande' under controlled atmosphere with high $\mathrm{CO}_{2}$ concentrations, $20 \% \mathrm{O}_{2}$ and cold storage $\left(10 \pm 1^{\circ} \mathrm{C}\right.$ and $95 \pm 2 \%$ $\mathrm{RH})$. Vertical bars represent the error $(\mathrm{B}, \mathrm{C})$. Appearance grades: $3=$ great; $2=$ good; $1=$ bad; and $0=$ very bad). Piracicaba, ESALQ, 2009.

lógica ao aumento de $\mathrm{CO}_{2}$ atmosférico, ou indicativo de frutos excessivamente maduros (Zaldivar et al., 2007). Essa constatação pode explicar os teores de atmosferas de armazenamento.

Não foi observada diferença estatística entre os tratamentos para a perda de massa acumulada. A redução na massa dos morangos foi inferior a $1,5 \%$ ao longo do armazenamento, demonstrando a eficiência da técnica usada para o controle da atmosfera e da umidade relativa (dados não apresentados). De acordo com García et al. (1998), os morangos perdem o valor comercial quando a perda de massa é superior a $6 \%$.

As atmosferas com 20 e $40 \%$ de $\mathrm{CO}_{2}$ proporcionaram aos morangos 'Oso Grande' manutenção da aparência, menor incidência de doenças e baixa produção de acetaldeído e etanol, além de demonstrarem a menor perda da firmeza (Figura 2A). Almenar et al. (2006) também observaram manutenção da aparência em morangos armazenados com atmosfera enriquecida com 12 e $20 \%$ de $\mathrm{CO}_{2}$. Pelayo et al. (2003) corroboram com os resultados obtidos, relatando que a atmosfera enriquecida com $20 \%$ de $\mathrm{CO}_{2}$ apresentou a melhor manutenção da firmeza da polpa de morangos 'Selva' e 'Diamante' por 12 dias, quando armazenados a $5^{\circ} \mathrm{C}$.

Observou-se na cor externa dos morangos, tendência de aumento nos valores da luminosidade (Figura 2B) e do ângulo de cor, com a manutenção da cromaticidade (Tabela 1), durante o armazenamento em todos os tratamentos. Os frutos armazenados com 20 e $40 \%$ de $\mathrm{CO}_{2}$ apresentaram as menores alterações na cor da casca como pode se notar na reduzida variação de luminosidade (Figura $2 \mathrm{~B}$ ) e na manutenção dos valores de ângulo de cor e na cromaticidade durante o armazenamento (Tabela 1). Pelayo et al. (2003), estudando morangos 'Diamante' e 'Selva' em atmosfera enriquecida com $20 \%$ de $\mathrm{CO}_{2}$ e não observaram diferenças na luminosidade e no ângulo de cor ao longo do armazenamento refrigerado $\left(5^{\circ} \mathrm{C}\right)$.

Foi detectada redução na cromaticidade nos morangos armazenados a $80 \%$ de $\mathrm{CO}_{2}$ (Tabela 1). Esta redução pode estar relacionada ao efeito do alto $\mathrm{CO}_{2}$ (Gorny \& Kader, 1994), que influencia nas reações bioquímicas e fisiológicas que catalisam a síntese de antocianina, sendo este o principal pigmento da coloração vermelha do morango (Aaby 


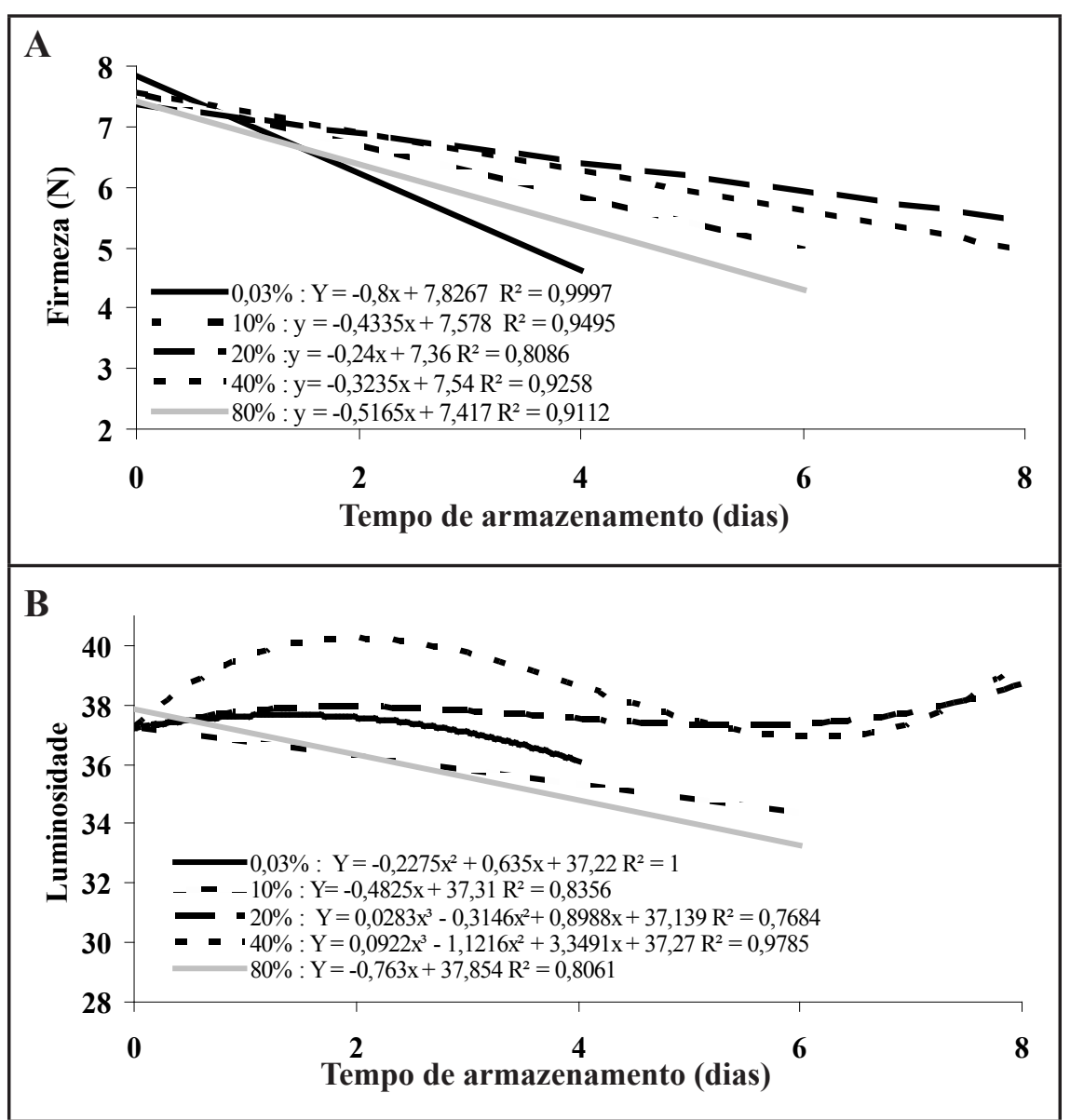

Figura 2. Evolução da firmeza (A) e da luminosidade (B), em morangos 'Oso Grande' submetidos a atmosfera controlada com distintas concentrações de $\mathrm{CO}_{2}$ associadas a $20 \%$ de $\mathrm{O}_{2}$, em armazenamento refrigerado $\left(10 \pm 1^{\circ} \mathrm{C}\right.$ e $95 \pm 2 \%$ UR) (firmness (A) and brightness (B) of strawberries 'Oso Grande' under controlled atmosphere with high $\mathrm{CO}_{2}$ concentrations, 20\% $\mathrm{O}_{2}$ and cold storage $\left(10 \pm 1^{\circ} \mathrm{C}\right.$ and $\left.95 \pm 2 \% \mathrm{RH}\right)$. Piracicaba, ESALQ, 2009. et al., 2005). Os dados obtidos neste experimento demonstraram que apenas concentrações acima de $40 \%$ de $\mathrm{CO}_{2}$ acarretaram mudanças na coloração de morango ‘Oso Grande' quando armazenados a $10^{\circ} \mathrm{C}$, deixando-os sem brilho e com tom vermelho-escuro.

Notou-se neste caso que houve diferença estatística na cor externa dos morangos, porém esta diferença foi visualmente sutil. Brackmann et al. (2001) obtiveram resposta semelhante, onde os tratamentos com $\mathrm{CO}_{2}$ apresentaram diferenças estatísticas significativas para os morangos armazenados a $20^{\circ} \mathrm{C}$; contudo, a diferença na cor foi pequena e visualmente inexpressiva.

O teor de sólidos solúveis não foi influenciado pelas concentrações de $\mathrm{CO}_{2}$ e nem pelo tempo de armazenamento, cujos valores médios foram de $7,2^{\circ}$ Brix (dados não mostrados). Resultados semelhantes foram observados em morangos 'Aroma' e 'Diamante' armazenados com $20 \%$ de $\mathrm{CO}_{2}$. Entretanto, morangos da cultivar 'Selva' apresentaram indícios de redução nos teores de sólidos solúveis ao longo do armazenamento (Palayo et al., 2003).

O menor teor de acidez titulável ocorreu nos frutos armazenados com $80 \%$ de $\mathrm{CO}_{2}(0,77 \mathrm{~g}$ de ácido cítrico $\left.100 \mathrm{~g}^{-1}\right)$. Os teores de acidez variaram

Tabela 1. Efeito da interação entre o tempo de armazenamento $\left(10 \pm 1^{\circ} \mathrm{C}\right.$ e $\left.95 \pm 2 \% \mathrm{UR}\right)$ e as distintas concentrações de $\mathrm{CO}_{2}$ em morangos 'Oso Grande' nas variáveis cromaticidade e ângulo de cor (effect of the interaction between storage time $\left(10 \pm 1^{\circ} \mathrm{C}\right.$ and $\left.95 \pm 2 \% \mathrm{RH}\right)$ and $\mathrm{CO} 2$ concentrations in strawberries 'Oso Grande' on chromaticity and hue). Piracicaba, ESALQ, 2009.

\begin{tabular}{|c|c|c|c|c|c|c|c|}
\hline \multirow{2}{*}{ Variável } & \multirow{2}{*}{ Dias } & \multicolumn{6}{|c|}{ Concentrações de $\mathrm{CO}_{2}(\%)$} \\
\hline & & $\mathbf{0 , 0 3}$ & 10 & 20 & 40 & 80 & Dms (5\%) \\
\hline \multirow{6}{*}{ Cromaticidade } & 0 & $31,42 \mathrm{Aa}$ & $31,42 \quad \mathrm{Ba}$ & $31,42 \mathrm{Aa}$ & $31,42 \mathrm{Aa}$ & $31,42 \mathrm{Aa}$ & 3,72 \\
\hline & 2 & $31,50 \mathrm{Aa}$ & $29,99 \mathrm{Ba}$ & $29,91 \mathrm{Aa}$ & $31,72 \mathrm{Aa}$ & $31,59 \mathrm{Aa}$ & 3,72 \\
\hline & 4 & $33,57 \mathrm{Aa}$ & $33,20 \mathrm{ABa}$ & $31,02 \mathrm{Aa}$ & $30,33 \mathrm{Aa}$ & $26,54 \mathrm{Bb}$ & 3,72 \\
\hline & 6 & - & $36,41 \mathrm{Aa}$ & $31,10 \mathrm{Ab}$ & $32,47 \mathrm{Ab}$ & $25,02 \mathrm{Bc}$ & 3,51 \\
\hline & 8 & - & - & $28,48 \mathrm{Ab}$ & $31,36 \mathrm{Aa}$ & - & 2,67 \\
\hline & Dms (5\%) & 3,19 & 3,51 & 3,72 & 3,72 & 3,51 & \\
\hline \multirow{6}{*}{ Ângulo de Cor } & 0 & $29,32 \mathrm{Aa}$ & $29,32 \mathrm{Aa}$ & $29,32 \mathrm{~A} \mathrm{a}$ & $29,32 \mathrm{Aa}$ & $29,32 \mathrm{ABa}$ & 4,23 \\
\hline & 2 & $28,68 \mathrm{Aa}$ & $32,28 \mathrm{Aa}$ & $28,66 \mathrm{Aa}$ & $32,26 \mathrm{Aa}$ & $32,10 \mathrm{Aa}$ & 4,23 \\
\hline & 4 & $31,38 \mathrm{Aa}$ & $30,15 \mathrm{Aa}$ & $31,18 \mathrm{~A} a$ & $29,45 \mathrm{Aa}$ & $27,57 \mathrm{Ba}$ & 4,23 \\
\hline & 6 & - & $29,38 \mathrm{Aa}$ & $30,40 \mathrm{Aa}$ & $30,34 \mathrm{Aa}$ & $22,98 \quad \mathrm{Cb}$ & 3,98 \\
\hline & 8 & - & - & $31,96 \mathrm{Aa}$ & $32,64 \mathrm{Aa}$ & - & 3,04 \\
\hline & Dms $(5 \%)$ & 3,63 & 3,98 & 4,23 & 4,23 & 3,98 & \\
\hline
\end{tabular}

Médias seguidas de pelo menos uma letra, maiúscula na coluna e minúscula na linha, para cada parâmetro avaliado, não diferem entre si pelo teste de Tukey $(\mathrm{p}<0,05)$ (means followed by at least one letter, uppercase in column and lowercase in line, for each parameter evaluated, are not different by the Tukey test $(\mathrm{p}<0,05)$. 


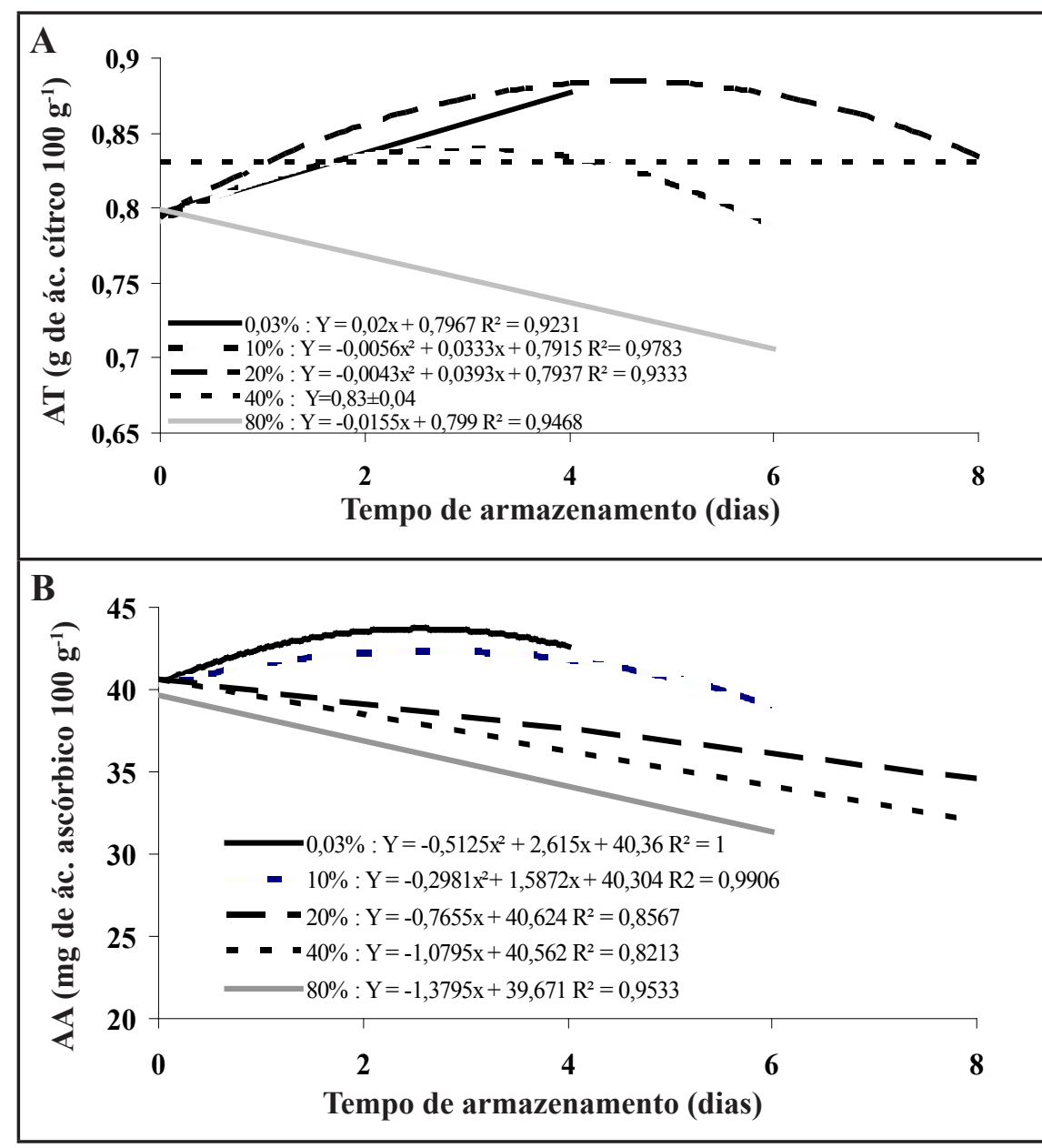

Figura 3. Evolução da acidez titulável (A) e do acido ascórbico (B) em morangos 'Oso Grande' submetidos à atmosfera controlada com distintas concentrações de $\mathrm{CO}_{2}$ associada a $20 \%$ de $\mathrm{O}_{2}$ em armazenamento refrigerado $\left(10 \pm 1^{\circ} \mathrm{C}\right.$ e $\left.95 \pm 2 \% \mathrm{UR}\right)$ (titratable acidity (A) and ascorbic acid (B) in strawberries 'Oso Grande' under controlled atmosphere with high $\mathrm{CO}_{2}$ concentrations, $20 \% \mathrm{O}_{2}$ and storage $\left(10 \pm 1^{\circ} \mathrm{C}\right.$ and $\left.\left.95 \pm 2 \% \mathrm{RH}\right)\right)$. Piracicaba, ESALQ, 2009.

de 0,79 a $0,85 \mathrm{~g}$ de ácido cítrico $100 \mathrm{~g}^{-1}$ durante o armazenamento (Figura $3 \mathrm{~A}$ ). Os morangos submetidos à atmosfera controle $\left(0,03 \%\right.$ de $\left.\mathrm{CO}_{2}\right)$ demonstraram uma leve tendência de aumento na acidez titulável. Já os frutos com $80 \%$ de $\mathrm{CO}_{2}$ apresentaram redução. A atmosfera com $40 \%$ de $\mathrm{CO}_{2}$ proporcionou aos morangos estabilidade em relação à acidez titulável. Pelayo et al. (2003) obtiveram resultados semelhantes para morangos 'Selva', 'Diamante' e 'Aromas', onde apresentaram variação de no máximo $0,09 \%$ no teor de acidez titulável, durante o armazenamento sob atmosfera com $20 \%$ de $\mathrm{CO}_{2}$ a $5^{\circ} \mathrm{C}$.

Os resultados obtidos neste trabalho demonstraram que os morangos da cv. Oso Grande a $10^{\circ} \mathrm{C}$ suportaram atmosferas de armazenamento com níveis de até $40 \%$ de $\mathrm{CO}_{2}$, sem apresentarem
1997). Outra hipótese é a descrita por Hausladen \& Kunert (1990), na qual o alto teor de $\mathrm{CO}_{2}$ inibiria as enzimas monodehidro- e/ou dehidroascorbato-redutase, a-glutadiona e dos doadores de elétrons NADP e NADPH, reduzindo assim a biossíntese do ácido ascórbico.

Esses processos podem ocorrer simultaneamente e, quando associados às altas concentrações de acetaldeído e etanol, podem ter proporcionado maior gasto de ácido ascórbico nos frutos sob $80 \%$ de $\mathrm{CO}_{2}$ em relação aos demais.

Este trabalho demonstrou que morangos 'Oso Grande' armazenados sob refrigeração $\left(10^{\circ} \mathrm{C}\right)$ e atmosfera controlada ( $40 \%$ de $\mathrm{CO}_{2}$ associados a $20 \%$ de $\mathrm{O}_{2}$ ) podem se conservar comercializáveis por até oito dias.

O uso de atmosfera controlada com $40 \%$ de $\mathrm{CO}_{2}$ mostrou-se eficaz na conservação de morangos 'Oso Grande' a $10^{\circ} \mathrm{C}$, proporcionando a manutenção da qualidade comercial, como pode ser comprovada pela reduzida incidência de doença e retardamento da senescência (nota de aparência e coloração), não acarretou o processo de respiração anaeróbica (acetaldeído e etanol) e preservou as características químicas (acidez, sólidos solúveis e ácido ascórbico).

\section{AGRADECIMENTO}

Os autores agradecem à FAPESP pelo apoio financeiro a esta pesquisa (Processo 2008/04553-6).

\section{REFERÊNCIAS}

Os teores de ácido ascórbico foram reduzidos com o aumento da porcentagem de $\mathrm{CO}_{2}$ na atmosfera de armazenamento, sendo o menor teor de ácido ascórbico encontrado nos morangos acondicionados com $80 \%$ de $\mathrm{CO}_{2}$. Houve diminuição neste teor ao longo do armazenamento, passando de $40 \mathrm{mg}$ de ácido ascórbico $100 \mathrm{~g}^{-1}$ no início para $32 \mathrm{mg}$ de ácido ascórbico $100 \mathrm{~g}^{-1}$ ao final do sexto dia de armazenamento (Figura 3B).

É possível que a redução no teor de ácido ascórbico durante o armazenamento seja devida à oxidação deste composto em ácido 2,3 diketo-glucónico, reação essa, estimulada por altas concentrações de $\mathrm{CO}_{2}$ (Agar et al.,
A.O.A.C. 2005. Official methods of analysis of the Association of Official Analytical Chemists International. 18 ed. Gaithersburg, Maryland. 2005. Phenolic composition and antioxidant activities in flesh and achenes of strawberries (Fragaria ananassa). Journal of Agricultural and Food Chemistry 53: 4032-4040.

AGAR IT; STREIF J; BANGERTH F. 1997. Effect of high $\mathrm{CO}$ and controlled atmosphere (CA) on the ascôrbic and dehydroascorbic acid content of some berry fruits. Postharvest Biology and Technology 11: 47-55.

ALMENAR E; FERNÁNDEZ-MUÑOZ P; LAGARÓN JM; CATALÁ R; GAVARA, R. 2006. Controlled atmosphere storage of wild strawberry fruit (Fragaria vesca L.). Journal of Agricultural and Food Chemistry 54: 86-91.

ANTUNES LEC; DUARTE FILHO JD; CALEGARIO FF; COSTA H; REISSER
AABY K; SKREDE G; WROLSTAD RE. 
JUNIOR C. 2007. Produção integrada de morango (PIMo) no Brasil. Informe Agropecuário 28: 34-39.

BRACKMANN A; HUNSCHE M; WACLAVOWSKY AJ; DONAZZOLO J. 2001. Armazenamento de morangos cv. Oso Grande (Fragaria Ananassa L.) sob elevadas pressões parciais de $\mathrm{CO}_{2}$. Revista Brasileira de Agrociência 7: 10-14.

CALBO AG. 1989. Adaptação de um fluxcentro para estudos de trocas gasosas e um método de aferição de capilares. Pesquisa Agropecuária Brasileira 24: 733-739.

CERQUEIRATS; CUNHA JÚNIOR LC; CALBO AG; JACOMINO AP. 2009. Flowboard for postharvest gas mixtures applications to fruits and vegetables without waste of gas. In: INTERNATIONAL CONTROLLED AND MODIFIED ATMOSPHERE RESEARCH CONFERENCE, $10^{\text {th }}$. Anais... Antalya, p. 56-56

CHITARRA MIF; CHITARRA AB. 2005. Póscolheita de frutas e hortaliças: fisiologia e manuseio. Lavras: FAEPE. 783p.

FERNÁNDEZ-TRUJILLO JP; NOCK JF; WATKINS CB. 2007. Antioxidant enzyme activities in strawberry fruit exposed to high carbon dioxide atmospheres during cold storage. Food Chemistry 104: 1425-1429.

FLORES-CANTILLANO RF. 2005. Colheita e pós-colheita. In: PEREIRA DP; BANDEIRA DL; QUINCOZES ERF (ed). SISTEMA DE PRODUÇÃO DO MORANGO. Pelotas. Embrapa Clima Temperado. (Embrapa Clima Temperado. Sistema de produção, 5). Disponível em: http://sistemasdeproducao. cnptia.embrapa.br/FontesHTML/Morango/ SistemaProducaoMorango/cap12.htm. Acessado em 10 outubro de 2010.

FONSECA SC; OLIVEIRA FAR; BRECHT JK. 2002. Modelling respiration rate of fresh fruits and vegetables for modified atmosphere packages: a review. Jounal of Food Engineering. 53: 99-119.

GARCÍA JM; MEDINA RJ; OLÍAS JM. 1998. Quality of strawberries automatically packed in different plastic films. Journal of Food Science 63: 1037-1041.

GORNY, JR; KADER, AA. 1994. The mode of $\mathrm{CO}_{2}$ action on ACC oxidase and its role in inhibition of ethylene biosynthesis. HortScience 29:533.

HAUSLADEN A; KUNERT KJ. 1990. Effects of artificially enhanced levels of ascorbate and glutathione on the enzymes monodehydroascorbate reductase, dehydroascorbate reductase and glutathion reductase in spinach (Spinacia oleracea). Physiolgy Plant 79: 384-388.

KE D; EL-SHEIKH T; MATEOS M; KADER AA.
1993. Anaerobic metabolism of strawberries under elevated $\mathrm{CO}_{2}$ and reduced $\mathrm{O}_{2}$ atmospheres. Acta Horticulturae 343: 93-99.

McGUIRE RG. 1992. Reporting of objective color measurements. HortScience 27: 1254-1255.

PELAYO C, EBELER SE, KADER AA. 2003; Postharvest life and flavor quality of three strawberry cultivars kept at $5^{\circ} \mathrm{C}$ in air or air $+20 \mathrm{kPaCO}$. Postharvest Biology Technolchnology 27: 171-183

SHAMAILA MM; POWRIE WD; SKURA BJ. 1992. Sensory evaluation of strawberry fruit stored under modified atmosphere packaging (MAP) by quantitative descriptive analysis. Journal of Food Science, 57: 1168-1172.

STROHECKER RL; HENNING HM. 1967. Analisis de vitaminas: métodos comprobados. Madrid: Paz Montalvo. 428 p.

VAN DER STEEN C; JACXSENS L; DEVLIEGHERE F. 2002. Combining high oxygen atmospheres with low oxygen modified atmosphere packaging to improve the keeping quality of strawberries and raspberries. Postharvest Biology and Technology 26: 49-58.

ZALDIVAR CP; ABDA, JB.; EBELER SE; KADER AA. 2007. Quality and chemical changes associated with flavor of camarosa strawberries in response to a $\mathrm{CO}_{2}$ enriched atmosphere. Hortscience 42: 299-303. 